\title{
Age, gender and drug therapy influences on Tpeak-tend interval and on electrical risk score
}

\author{
Gianfranco Piccirillo ${ }^{a}$, Federica Moscucci ${ }^{\mathrm{a}, *}$, Marcella Fabietti $^{\mathrm{a}}$, Claudia Di Iorio ${ }^{\mathrm{a}}$, Fabiola Mastropietri ${ }^{\mathrm{a}}$, \\ Teresa Sabatino ${ }^{\text {a }}$, Davide Crapanzano ${ }^{a}$, Gaetano Bertani ${ }^{a}$, Giulia Zaccagnini ${ }^{\mathrm{a}}$, \\ Ilaria Lospinuso $^{\text {a }}$, Damiano Magrì ${ }^{\text {b }}$ \\ a Dipartimento di Scienze Cliniche, Internistiche, Anestesiologiche e Cardiovascolari, "Sapienza" University of Rome, Viale del Policlinico, 00185 Rome, Italy \\ b Dipartimento di Medicina Clinica e Sperimentale, Sant'Andrea Hospital, “Sapienza" University of Rome, Via di Grottarossa 1035/1039, 00189 Rome, Italy
}

\section{A R T I C L E I N F O}

Available online $\mathrm{xxxx}$

Keywords:

Electrical risk score

Mortality

T peak-tend interval

QTc

Aging

Gender

Repolarization phase

\begin{abstract}
A B S T R A C T
Background and objectives: Electrical risk score (ERS) has been proposed as easy, inexpensive test to stratify of sudden cardiac death $(\mathrm{SCD})$ risk in subjects with normal left ventricular function. Potentially, aging, gender and drugs can influence ERS affecting two on six electrical markers, particularly, those based on the repolarization. Aim of this study was to establish aging, gender and drug therapy possible influences on ERS and mortality in elderly patients.

Method: 237 consecutive, low SCD risk-outpatients with asymptomatic and treated cardiovascular risk factors were analyzed. Six simple ECG markers composed ERS: heart rate ( $>75 \mathrm{bpm})$; left ventricular hypertrophy (Sokolow-Lyon criteria); delayed QRS transition zone $(\geq \mathrm{V} 4)$, frontal QRS-T angle $\left(>90^{\circ}\right)$, long $\mathrm{QT}_{\text {Bazett }}$; long T peak to $T$ end interval $\left(T_{\mathrm{p}-\mathrm{e}}\right.$ ). We obtained ERS in 237 outpatients, grouped according age ( $<40 \mathrm{ys}, \geq 40$ to $<60$ ys and $\geq 60 \mathrm{ys}$ ), gender and drug therapy with or without possible influence on the repolarization phase. Results: Two-hundred-thirty-seven patients were grouped respectively in the following age classes: $<40$ years old; $\geq 40$ to $<60$ years old and $\geq 60$ years old. ERS $(p<0.05)$, $\mathrm{QT}_{\text {Bazett }}(p<0.001), \mathrm{T}_{\mathrm{p}-\mathrm{e}}(p<0.001)$ were higher in older subjects independently from gender, drug therapy and cardiovascular comorbidity. After two years we reported a 7.3\% of mortality in the older groups; age (deceased versus survivors: $80 \pm 4$ versus $73 \pm 7$ years, $p<0.05$ ) and $\mathrm{T}_{\mathrm{p} \text {-e }}$ (deceased versus survivors: $117 \pm 15$ versus $93 \pm 21 \mathrm{~ms}, p<0.05$ ) were significantly lower in survivors, multivariable logistic regression analysis selected only the $\mathrm{T}_{\mathrm{p}-\mathrm{e}}$ as significant risk factor for total mortality (odd ratio $1.06,95 \% \mathrm{CI}: 1.01-1.12, p<0.05$ ).

Conclusion: Aging was associated to the ERS and repolarization phase derangement. $\mathrm{T}_{\mathrm{p} \text {-e }}$ should be considered a marker of total mortality rather than SCD in the over sixty years old patients.
\end{abstract}

(c) 2020 Elsevier Inc. All rights reserved.

\section{Introduction}

The holy grail of modern cardiovascular medicine was to find a simple and inexpensive test capable to identify subjects, candidate to malignant arrhythmias in a population with low risk of sudden cardiac death (SCD). Recently, some authors proposed the electrical risk score (ERS) [1], this score, based on standard 12 lead ECG, should be able to detect subjects with reasonable risk of SCD. This ERS was composed by six different ECG data: heart rate, LVH, QRS transition zone, QRS-T angle, QT $\left(\mathrm{QT}_{\text {Bazett }}\right)$, and Tpeak to-Tend segment $\left(\mathrm{T}_{\mathrm{p}-\mathrm{e}}\right)$, then two on six are based on the left ventricular repolarization. Recently, two different studies reported that the increase this score it was related with high risk SCD in two different populations [1,2]. In fact, these authors

\footnotetext{
* Corresponding author.

E-mail address: federica.moscucci@uniroma1.it (F. Moscucci).
}

reported a high risk of SCD both in apparently healthy subjects with normal ejection fraction [1] and the subjects with degenerative aortic stenosis [2]. Because left ventricular repolarization duration $\left(\mathrm{QT}_{\text {Bazett, }}\right.$, $\mathrm{T}_{\mathrm{p}-\mathrm{e}}$ ) could be affected by aging, gender and drug administration and, it could play also a decisive rule in this score. Aim of this study was to evaluate the possible influence of these three different clinical parameters on repolarization data, the ERS and the mortality in old patients with low risk of SCD.

\section{Methods and materials}

\section{Participants}

A total of 237 consecutive outpatients received a standard 12-lead electrocardiogram between April and December 2016. All these patients had low risk of SCD, in fact they reported a asymptomatic history of 
treated vascular risk factors (hypertension, diabetes, hypercholesterolemia) or chronic heart failure with normal systolic function, with or without mild symptoms (I or II NYHA), stable or treated coronary diseases etc. We did not included patients with severe heart failure (III-IV NYHA class), dilated cardiomyopathy with low ejection fraction, aortic valve stenosis or hypertrophic cardiomyopathy or others known diseases with high risk of SCD or patients with implantable cardioverter defibrillator device (ICD) indication. All participants provided their written informed consent. We grouped the patients in base to the age, or drug therapy with possible effect on the repolarization or gender. According to age the groups were three: subjects aged $<40$ years, $\geq 40$ to $<60$ years, $\geq 60$ years. In the same manner, we grouped the patients according to the drug therapy: subjects without therapy with possible effect on the left ventricular repolarization phase; subjects with one drug with the possible effect on the left ventricular repolarization phase; and subjects with two or more drugs with possible effect on the ventricular repolarization phase. The drugs with possible effect on QT were obtained by web site: www.crediblemeds. org. In the our study population, we considered the following drugs to have not influence on repolarization phases: antiplatelet drugs; ACE inhibitors; sartans; $\beta$-blockers; statins; diltiazem or verapamil; dihydropyridine calcium channel blockers; $\alpha$-adrenoreceptor-blockers; oral anticoagulants; aldosterone antagonists; digoxin; potassium; levothyroxine; methimazole; nitrates; $₫$-3-polynsatured fatty acid; ivabradine; insulin; oral antidiabetic drugs; $\beta$-2-adrenoreceptoragonists; anticholinergic bronchodilatators; corticosteroids; pain reliefs; benzodiazepines; dopa-decarboxylase inhibitors; other antiparkinson drugs (selegiline, pramipexole); gabepentin; lamotrigine; eletriptam; vitamin D3; 5- $\alpha$-Reductase inhibitors; lactulose; antivertigo drugs; allopurinol. On the contrary, we considered the following drugs to have a possible influence on repolarization phases: protonic pomp inhibitors, histamine-2-receptors blockers; furosemide; propafenone; flecainide; amiodarone; ranolazina; antidepressants: selective serotonin reuptake inhibitor (SSRI), serotonin-norepinephrin reuptake inhibitor (SNRI), noradrenergic and specific serotonergic antidepressant (NSSA) and triclycs; neuroleptics; acetylcholinesterase inhibitors; memantine; pregabalin; amantadine; carbamazepine; valproate; levetiracetam; antihistamines; macrolides or chinolones; tizanidine; domperidone; hidroxychloroquine.

\section{Electrocardiographic analysis}

Each enrolled patient had a stored resting 12-lead ECG (Esaote, model: MyCardioPad/XL 12 channels, Florence, Italy) available for the analysis (paper speed was $25 \mathrm{~mm} / \mathrm{s}$ and calibration $10 \mathrm{~mm} / \mathrm{mV}$ ). Those patients with ECG evidence of atrial flutter or II/III-degree atrioventricular block, pre-excitation, or paced rhythm were excluded from analysis. Heart rate, LVH (Sokolow-Lyon criteria), delayed QRS transition zone, frontal QRS-T angle, long $\mathrm{QT}_{\text {Bazett }}$, and long $\mathrm{T}_{\mathrm{p}-\mathrm{e}}$ composed the ERS $[1,2]$. In this score 1 and 0 were assigned respectively for an abnormal or normal ECG electrical value, and a score $\geq 4$ was considered predictive of high risk for mortality [1,2]. Abnormal ECG data were considered as the following: a heart rate $>75 \mathrm{bpm}$, QRS duration $>110 \mathrm{~ms}$, the left ventricular hypertrophy, achieved with the Sokolow-Lyon criteria, the QRS transition $\geq 4$ th precordial lead (V4), the frontal QRSangle $>90^{\circ}$, and $\mathrm{T}_{\mathrm{p}-\mathrm{e}}>89 \mathrm{~ms}[1,2]$. Frontal QRS-T angle was calculated as the difference between $\mathrm{T}$ wave and $\mathrm{QRS}$ axis; in case the difference between QRS and T axis was higher than $180^{\circ}$, QRT-T angle was calculated by subtracting these achieved degrees from $360^{\circ}$ [3]. Moreover, with regard to repolarization phase, we corrected the QT intervals by the Bazett method $\left(\mathrm{QT}_{\text {Bazett: }}\right.$ Q QT/RR $\left.\mathrm{RR}^{0.5}\right)$. Respectively, a $\mathrm{QT}_{\text {Bazett }}$ interval $>450 \mathrm{~ms}$ for men and $>460 \mathrm{~ms}$ for women. Tpeak-tend was manually evaluated with tangent method using an electronic caliper and also with an online program uploading scanned copies. The same skilled cardiologist (GP) analyzed all ECGs in order to eliminate inter-observer bias.

The patients provided informed consent for the use of their data for research purpose and the study was in accordance with good clinical practice and the principles of the Declaration of Helsinki of clinical research involving human patients. Local Ethical Committee approved this study.

\section{Statistical analysis}

Normally distributed continuous variables are reported as mean and standard deviation and are compared using one-way analysis of variance and Bonferroni test. Non-normally distributed variables are expressed as median and inter-quartile range [IQR] and compared using the Kruskal-Wallis and Mann-Whitney $U$ tests. ERS' cut off was obtained from the Oregon Sudden Unexpected Death Study and the Atherosclerosis Risk in Communities Study [1]. Categorical variables are presented as frequencies and percentage and compared using the chi-squared test. Uni- and multivariable forward (A. Wald) stepwise logistic regression analysis were used to determine the association between all-cause mortality in the elders and the other selected clinical, or electrical covariates included in the study. Included covariates were: age, gender, heart rate, QRS, QTc, $\mathrm{T}_{\mathrm{p}-\mathrm{e}}$, QRS-T angle, QRS transition zone, transition zone, left ventricular hypertrophy (Sokolow-Lyon criteria) and ERS.

\section{Results}

Two-hundred-thirty-seven patients underwent a standard electrocardiogram; 72, 50 and 115 subjects were grouped respectively in the following age classes: $<40$ years old (young subjects); $\geq 40$ to $<60$ years old (middle age subjects) and $\geq 60$ years old (elders) (Table 1). BMI, systolic and diastolic blood pressure were significantly lower in the younger group $(p<0.0001)$, on the contrary the older groups reported the major comorbidities and drug treatments for these comorbidities (Table 1). The drug therapy was different in three age-groups. Especially in the elders, we reported a significant difference regarding to the cardiovascular drugs (antiplatelet, sartans, ACE inhibitors, dihydropyridine calcium channels blockers, oral anticoagulants, furosemide), pomp protonic inhibitions, $\alpha$-adrenoreceptor-blockers and 5 - $\alpha$-reductase inhibitors administration (Table 1 ) in comparison other the young and middle age subjects. We did not observed other statistic difference for other single drug administration between the groups. In conclusion, when we consider the overall burden of drugs with possible effect on repolarization the number of elders with 1 or 2 or more drugs with possible effect on repolarization were significantly higher than meddle age and younger patients $(p<0.001)$ (Table 1$)$. Obviously, the young subjects without therapy with possible effects on repolarization were higher significantly in comparison to the other two groups $(p<0.001)$ (Table 1$)$.

Elders showed a significantly higher of ERS ( $p<0.001), \mathrm{QT}_{\text {Bazett }}$ $(p<0.05)$ and $\mathrm{T}_{\mathrm{p}-\mathrm{e}}(p<0.001)$ than young and middle age subjects (Table 2); on the contrary, young group reported an increase of the LVH $(p<0.05)$ and the frontal QRS-T angle $(p<0.001)$ in comparison to the middle age and elders (Table 2). Subjects without any drug therapy with possible influence on QT were younger than others subjects (Table 3$)$ and these patients showed ERS $(p<0.05), \mathrm{T}_{\mathrm{p} \text {-e }}(p<0.001)$, QRS-T angle $(p<0.001)$ significantly different from subjects with one or two or more drugs with possible effects on QT. QT $\mathrm{Bazett}_{\text {was shorter }}$ also in subjects without $(p<0.001)$ or one drug $(p<0.05)$ with repolarization possible effect in comparison to patients with 2 or more drugs (Table 3).

When we considered the ERS and the other electrical markers in elderly group, we observed only one significant difference: the subjects with two drugs with possible effect on QT had a significant longer $\mathrm{QT}_{\text {Bazett }}(442 \pm 31 \mathrm{~ms}, p<0.05)$ than the subjects of the same age group without drug administration with QT effects ( $415 \pm 30 \mathrm{~ms})$. In fact, for example, $T_{p-e}$ was similar in elderly patients with different drugs administration (no drug: $91 \pm 15 \mathrm{~ms}$; 1 drug: $91 \pm 20 \mathrm{~ms} ; 2$ or more drugs: $98 \pm 23$; p:ns). 
Table 1

General characteristic of the study subjects.

\begin{tabular}{|c|c|c|c|c|}
\hline & \multirow{2}{*}{$\frac{\text { Age }<40 \text { years }}{\mathrm{N}: 72}$} & \multirow{2}{*}{$\frac{\text { Age } \geq 40<60 \text { years }}{\mathrm{N}: 50}$} & \multirow{2}{*}{$\frac{\text { Age } \geq 60 \text { years }}{\mathrm{N}: 115}$} & \multirow[t]{2}{*}{$p$} \\
\hline & & & & \\
\hline Age, years & $26 \pm 8^{* *}+4$ & $50 \pm 6^{* *}$ & $74 \pm 7$ & $<0.0001$ \\
\hline $\mathrm{M} / \mathrm{F}, \mathrm{n}$ & $32 / 40$ & $21 / 29$ & $53 / 62$ & ns \\
\hline BMI, $\mathrm{kg} / \mathrm{m}^{2}$ & $23 \pm 5^{*}+$ & $26 \pm 5$ & $25 \pm 4$ & $<0.0001$ \\
\hline SBP, mm Hg & $112 \pm 12 *+$ & $121 \pm 15^{* *}$ & $137 \pm 21$ & $<0.0001$ \\
\hline DBP, mm Hg & $72 \pm 10^{* *}+$ & $80 \pm 11$ & $78 \pm 9$ & $<0.0001$ \\
\hline Heart rate, $\mathrm{b} / \mathrm{m}$ & $67 \pm 10$ & $67 \pm 11$ & $64 \pm 9$ & ns \\
\hline Hypertension, n (\%) & $4(6)^{* *}$ & $8(16)^{* *}$ & $71(62)$ & $<0.0001$ \\
\hline Hypercholesterolemia, n (\%) & $2(3)^{*}$ & $3(6)$ & $22(19)$ & 0.0044 \\
\hline Diabetes, n (\%) & $1(1)^{*}$ & $1(2)^{*}$ & $15(13)$ & 0.0066 \\
\hline Myocardial ischemia, n (\%) & $0(0)^{*}$ & $1(2)$ & $10(9)$ & 0.0200 \\
\hline Chronic heart failure (I or II NYHA), n (\%) & $0(0)^{*}$ & $0(0)^{*}$ & $15(13)$ & 0.0006 \\
\hline Atrial fibrillation, $\mathrm{n}(\%)$ & $2(3)$ & $0(0)^{*}$ & 11(10) & 0.0323 \\
\hline Depression, $\mathrm{n}(\%)$ & $0(0)^{*}$ & $2(4)$ & $13(11)$ & 0.0111 \\
\hline Cognitive impairment, $\mathrm{n}(\%)$ & $0(0)^{*}$ & $0(0)$ & $7(6)$ & 0.0272 \\
\hline Migraine, $\mathrm{n}(\%)$ & $0(0)$ & $2(4)^{*}$ & $0(0)$ & 0.0266 \\
\hline Prostatic hypertrophy, n (\%) & $0(0)^{*}$ & $2(4)$ & $15(13)$ & 0.0047 \\
\hline Antiplatelet drug & $2(3)^{* *}$ & $4(8)^{* *}$ & $59(51)$ & $<0.0001$ \\
\hline Furosemide, n (\%) & $0(0)^{* *}$ & $4(8)$ & $20(17)$ & 0.0018 \\
\hline ACE/Sartans & $1(1)^{* *}$ & $8(16)^{*}$ & $60(52)$ & $<0.0001$ \\
\hline$\beta$-blockers, n (\%) & $2(3)^{* *}$ & $2(4)^{*}$ & $28(24)$ & $<0.0001$ \\
\hline Statins, $\mathrm{n}(\%)$ & $2(3)^{* *}$ & $4(8)^{*}$ & $33(29)$ & 0.0001 \\
\hline Dihydropyridine calcium channel blockers, n (\%) & $1(1)^{*}$ & $0(0)^{*}$ & $18(17)$ & 0.0005 \\
\hline$\alpha$-adrenoreceptor-blockers, n (\%) & $0(0)^{*}$ & $0(0)^{*}$ & $17(15)$ & 0.0062 \\
\hline Oral anticoagulants, $\mathrm{n}(\%)$ & $0(0)^{*}$ & $0(0)^{*}$ & $13(10)$ & 0.0015 \\
\hline Protonic pomp inihibithors, $\mathrm{n}(\%)$ & $5(7)^{* *}$ & $7(14)^{* *}$ & $52(45)$ & $<0.0001$ \\
\hline No drug with possible QT influence, $\mathrm{n}(\%)$ & $61(85)^{* *}$ & $36(62)^{* *}$ & $39(34)$ & 0.0007 \\
\hline 1 drug with possible QT influence, $\mathrm{n}(\%)$ & $6(8)^{*}$ & $8(16)$ & $39(34)$ & 0.0028 \\
\hline 2 or more drugs with possible QT influence, $\mathrm{n}(\%)$ & $5(7)^{*}$ & $6(12)^{*}$ & $37(32)$ & 0.0017 \\
\hline No drug with possible QT influence, $\mathrm{n}(\%)$ & $61(85)^{* *}$ & $36(62)^{* *}$ & $39(34)$ & 0.0007 \\
\hline
\end{tabular}

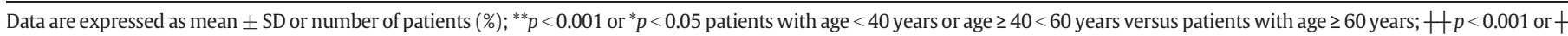
$p<0.05$ patients with age $<40$ years versus patients with age $\geq 40<60$ years.

At the end, we compare the ERS and other electrical markers between three age groups excluding the subjects with drug therapy with possible influence on QT, to assess the influence of aging on repolarization and ERS (Table 4$)$. $\mathrm{T}_{\mathrm{p}-\mathrm{e}}(p<0.001)$ and ERS $(p<0.05)$ was higher in elders (Table 4) in comparison to the other two groups; $\mathrm{QT}_{\mathrm{Bazett}}$ was longer only in older than young subjects $(p<0.05)$ (Table 4).

Considering the whole study population, we did not find any difference between the two genders (M/F:105/131), for age (54 \pm 23 vs $54 \pm 22$ years, p:ns), heart rate ( $67 \pm 11$ vs $68 \pm 11 \mathrm{~b} / \mathrm{m}$, p:ns), $\mathrm{T}_{\mathrm{p}-\mathrm{e}}$ ( $82 \pm 18$ vs $84 \pm 20 \mathrm{~ms}$, p:ns), QRS-T angle ( -9 [50] vs -3 [39] degree, p:ns) and ERS (1 [1] vs 1 [1], p:ns) On the contrary, $\mathrm{QT}_{\text {Bazett }}$ was significantly higher in the woman ( $411 \pm 35$ vs $420 \pm 29 \mathrm{~ms}, p<0.05)$ and LVH $(2.66 \pm 0.79$ vs $2.38 \pm 0.84 \mathrm{mV}, p<0.05)$ was higher in the males. The single age groups did not report any other statistic gender related differences except for the $\mathrm{QT}_{\text {Bazett }}$ in the woman young group (394 \pm 23 vs $409 \mathrm{~ms}, p<0.05$ ).
We found some unexpected data, when we compared elders with cardiovascular diseases (hypertension, chronic heart failure, ischemic cardiomyopathy and atrial fibrillation) versus the same age-group, but without cardiovascular diseases, we did not observe any difference in ERS and in each single electrical marker.

After at least 2 years (mean $2.3 \pm 0.5$ ) we recall all 115 elders and we were able to get in touch 68 (M/F: 28/40), that it was 59\% of original study population. In this period 5 (7.3\%) elders died (M/F: $3 / 2)$, one for SCD and four for cognitive decline, immobility syndrome and related infective complications. All deceased patients of this group had a daily intake of 2 or more drugs with possible effect on repolarization. Between the deceased and survival elders we find only two significant differences: age (deceased versus survivors: $80 \pm 4$ versus $73 \pm 7$ years, $p<0.05$ ) and $\mathrm{T}_{\mathrm{p}-\mathrm{e}}$ (deceased versus survivors: $117 \pm 15$ versus $93 \pm$ $21 \mathrm{~ms}, p<0.05)$. Univariable and multivariable logistic regression analysis selected only the $\mathrm{T}_{\mathrm{p}-\mathrm{e}}$ as significant risk factor for mortality (odd ratio $1.06,95 \% \mathrm{CI}: 1.01-1.12, p<0.05$ ).

Table 2

Electrocardiographic measures in patient groups with different age.

\begin{tabular}{|c|c|c|c|c|}
\hline & \multirow{2}{*}{$\begin{array}{l}\text { Age }<40 \text { years } \\
\mathrm{N}: 72\end{array}$} & \multirow{2}{*}{$\begin{array}{l}\text { Age } \geq 40<60 \text { years } \\
\text { N:50 }\end{array}$} & \multirow{2}{*}{$\frac{\text { Age } \geq 60 \text { years }}{\mathrm{N}: 115}$} & \multirow[t]{2}{*}{$p$} \\
\hline & & & & \\
\hline Heart rate, b/m & $69 \pm 10$ & $69 \pm 12$ & $66 \pm 11$ & ns \\
\hline $\mathrm{QT}_{\text {Bazett, }} \mathrm{ms}$ & $403 \pm 23^{* *}$ & $411 \pm 30^{*}$ & $426 \pm 34$ & $<0.0001$ \\
\hline $\mathrm{T}_{\mathrm{p}-\mathrm{e}, \mathrm{ms}}$ & $76 \pm 12^{* *}$ & $71 \pm 13^{* *}$ & $93 \pm 20$ & $<0.0001$ \\
\hline QRS-T angle, degree & $14[30]^{* *}+$ & $-4[28]^{*}$ & $-22[58]$ & $<0.0001$ \\
\hline QRS transition zone, & $2.79 \pm 0.88$ & $2.86 \pm 0.98$ & $2.71 \pm 1.38$ & ns \\
\hline Electrocardiographic left ventricular hypertrophy, mV & $2.86 \pm 0.83^{* *}+$ & $2.30 \pm 0.59$ & $2.38 \pm 0.85$ & $<0.0001$ \\
\hline Electrical risk score & $0.60[1]^{* *}$ & $0.46[1]^{* *}$ & $1.11[1]$ & $<0.0001$ \\
\hline Subjects with Electrical risk score $=0$ & $39(54)$ & $31(62)$ & $33(29)$ & 0.017 \\
\hline Subjects with Electrical risk score $\geq 4$ & $0(0)$ & $0(0)$ & $4(3)$ & ns \\
\hline
\end{tabular}

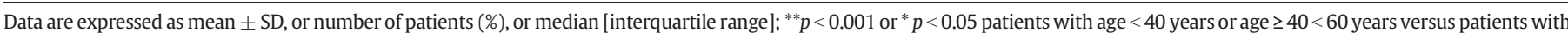
age $\geq 60$ years; $+p<0.001$ or $+p<0.05$ patients with age $<40$ years versus patients with age $\geq 40<60$ years. 


\begin{tabular}{|c|c|c|c|c|}
\hline & $\begin{array}{l}\text { No drug with possible QT } \\
\text { influence }\end{array}$ & $\begin{array}{l}1 \text { drug with possible QT } \\
\text { influence }\end{array}$ & $\begin{array}{l}2 \text { or more drugs with possible QT } \\
\text { influence }\end{array}$ & $p$ \\
\hline & $\mathrm{N}: 135$ & $\mathrm{~N}: 52$ & $\mathrm{~N}: 50$ & \\
\hline Age, years & $44 \pm 21^{* *}+十$ & $66 \pm 15$ & $69 \pm 18$ & $<0.0001$ \\
\hline Heart rate, $\mathrm{b} / \mathrm{m}$ & $68 \pm 11$ & $66 \pm 12$ & $69 \pm 11$ & Ns \\
\hline $\mathrm{QT}_{\text {Bazett }}, \mathrm{ms}$ & $408 \pm 26^{* *}$ & $416 \pm 35^{*}$ & $436 \pm 34$ & $<0.0001$ \\
\hline $\mathrm{T}_{\mathrm{p}-\mathrm{e}, \mathrm{ms}}$ & $78 \pm 15^{* *}+$ & $86 \pm 22$ & $93 \pm 87$ & $<0.0001$ \\
\hline QRS-T angle, degree & $4[39]^{* *}+$ & $-20[49]$ & $-18[51]$ & $<0.0001$ \\
\hline QRS transition zone, & $2.79 \pm 0.98$ & $2.68 \pm 1.37$ & $2.79 \pm 1.38$ & Ns \\
\hline Electrocardiographicleft ventricular hypertrophy, mV & $2.62 \pm 0.83$ & $2.36 \pm 0.82$ & $2.35 \pm 0.88$ & Ns \\
\hline Electrical risk score & $0[1]^{*}+$ & $1[1]$ & $1[2]$ & 0.005 \\
\hline Subjects with Electrical risk score $=0$ & $71(53)$ & $17(33)$ & $15(30)$ & ns \\
\hline Subjects with Electrical risk score $\geq 4$ & $1(1)$ & $1(2)$ & $2(4)$ & ns \\
\hline
\end{tabular}

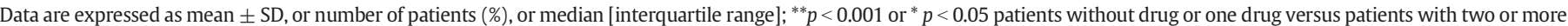
drugs with possible effect on repolarization; $+p<0.001$ or $+p<0.05$ patients without drug versus patients with one drug with possible effect on repolarization.

\section{Discussion}

The main important data of these study were: first of all, in over sixty year old patients with (Table 2 ) or without (Table 4) drug therapy with possible repolarization influence, we reported an increase of $\mathrm{QT}_{\text {Bazett }}, \mathrm{T}_{\mathrm{p}-}$ e and the ERS; secondly, because the $\mathrm{QT}_{\text {Bazett }}, \mathrm{T}_{\mathrm{p}-\mathrm{e}}$ and the ERS were higher in tall older patients, but especially in the older subjects without drug therapy with possible repolarization interference (Table 4), aging should be considered an independent factor capable to influence these three parameters; thirdly, gender and heart disease had not influence on these parameters in elderly patients. Finally, the abnormal $\mathrm{T}_{\mathrm{p}-\mathrm{e}}$ was the only parameter associated with a higher risk of mortality in over sixty-year-old patients and after short term follow-up.

As we previously pointed out, in our study, the repolarization was longer in over sixty-year-old independently from gender and drug therapy; regarding the gender, however, this datum was not novel, in fact a relation between age and QT has already been described [4]. In fact, in woman of child-bearing age, the estrogen or the testosterone absence [5] induces a longer QT (about 10 milliseconds) than the male subjects and, of course, after the menopause the repolarization duration is similar in both the genders. On the contrary, we did not find any gender related difference regarding $\mathrm{T}_{\mathrm{p}-\mathrm{e}}$, but we observed an age-related increase of this parameter in previous studies, using other methods, confirming the weakness of this part of repolarization phase in the elderly patients [6]. All these observations induced us to assume, reasonably, that it exists in old patients a repolarization related risk of SCD, even if we have not studied a statistically significant number of subjects; anyway, $\mathrm{T}_{\mathrm{p}-\mathrm{e}}$ was associated in total mortality risk in elderly subjects.

The supposable age-related mechanisms, capable to affect repolarization, could be numerous, but understudied. Obviously, the prolongation of this phase could involve an imbalance of the ion channel current control; for example, it was reported an abnormal cardiomyocyte calcium handling. In particular, L-type calcium channel current showed a slower inactivation and, similarly, these channels show increased activity and number [7]. Moreover, it could be also involved a reduction in outwardly directed potassium currents: in fact, it was recently reported an age-dependent remodeling of slow and rapid outward rectifying currents in experimental model. [8].

In conclusion, in this study we observed an increase of repolarization duration phase and ERS in older patients. ERS was not a predictor of SCD in these patients after two years, but the small size of examined sample and the short period of follow-up could be the causes of these inconclusive results. On the contrary, $\mathrm{T}_{\mathrm{p}-\mathrm{e}}$, a simple and inexpensive parameter based on the standard ECG, was an independent risk factor of mortality in these old patients. Gender, cardiac diseases and drugs with possible effect on repolarization did not influence the ERS, the repolarization and the outcome in patients over sixty without advanced heart failure.

\section{Disclosure/Acknowledgments}

Authors have not any conflict of interest in this paper to declare.

\section{CRediT authorship contribution statement}

Gianfranco Piccirillo:Conceptualization, Data curation, Formal analysis.Federica Moscucci:Writing - review \& editing.Marcella Fabietti:Investigation, Methodology, Data curation.Claudia Di Iorio:Investigation, Methodology, Data curation.Fabiola Mastropietri:Investigation, Methodology, Data curation.Teresa Sabatino:Investigation, Methodology, Data curation.Davide Crapanzano:Investigation, Methodology, Data curation.Gaetano Bertani:Investigation, Methodology, Data curation.Giulia Zaccagnini:Investigation, Methodology, Data curation.Ilaria Lospinuso:Investigation, Methodology, Data curation. Damiano Magrì:Supervision, Validation, Visualization, Writing - review \& editing.

Table 4

Electrocardiographic measures in patient groups with different age without drug therapy with possible influence on QT.

\begin{tabular}{|c|c|c|c|c|}
\hline & Age $<40$ years & Age $\geq 40<60$ years & Age $\geq 60$ years & $p$ \\
\hline & $\mathrm{N}: 61$ & $\mathrm{~N}: 36$ & $\mathrm{~N}: 38$ & \\
\hline Heart rate, $\mathrm{b} / \mathrm{m}$ & $68 \pm 10$ & $70 \pm 10$ & $66 \pm 13$ & ns \\
\hline $\mathrm{QT}_{\text {Bazett }}, \mathrm{ms}$ & $401 \pm 23^{*}$ & $414 \pm 26$ & $415 \pm 30$ & 0.009 \\
\hline $\mathrm{T}_{\mathrm{p}-\mathrm{e}, \mathrm{ms}}$ & $75 \pm 12^{* *}$ & $70 \pm 13^{* *}$ & $91 \pm 15$ & $<0.0001$ \\
\hline QRS-T angle, degree & $14[29]$ & $0[37]$ & $-14[57]$ & ns \\
\hline QRS transition zone, & $3 \pm 1$ & $3 \pm 1$ & $3 \pm 1$ & ns \\
\hline Electrocardiographic left ventricular hypertrophy, mV & $2.75[0.64]^{*}$ & $2.35[0.80]$ & $2.23[1.03]$ & 0.016 \\
\hline Electrical risk score & $0[1]^{*}$ & $0[1]^{*}$ & $1[2]$ & 0.04 \\
\hline Subjects with Electrical risk score $=0$ & $35(57)$ & $21(58)$ & 15(39) & ns \\
\hline Subjects with Electrical risk score $\geq 4$ & $0(0)$ & $(0)$ & $1(3)$ & ns \\
\hline
\end{tabular}

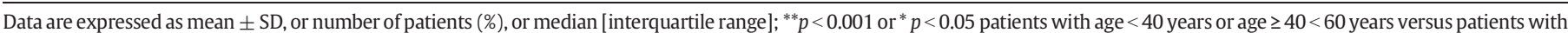
age $\geq 60$ years. 


\section{Declaration of competing interest}

All authors deny conflicts of interest in connection with the submitted article, nor industry relationship.

\section{References}

[1] Aro AL, Reinier K, Rusinaru C, Uy-Evanado A, Darouian N, Phan D, et al. Electrical risk score beyond the left ventricular ejection fraction: prediction of sudden cardiac death in the Oregon Sudden Unexpected Death Study and the Atherosclerosis Risk in Communities Study. Eur Heart J 2017;38(40):3017-25 Oct 21.

[2] Piccirillo G, Moscucci F, Mastropietri F, Di Iorio C, Mariani MV, Fabietti M, et al. Possible predictive role of electrical risk score on transcatheter aortic valve replacement outcomes in older patients: preliminary data. Clin Interv Aging 2018;13:1657-67 Sep 11.
[3] Chua KC, Teodorescu C, Reinier K, Uy-Evanado A, Aro AL, Nair SG, et al. Wide QRS-T angle on the 12-lead ECG as a predictor of sudden death beyond the LV ejection fraction. J Cardiovasc Electrophysiol 2016;27(7):833-9 Jul.

[4] Rabkin SW, Cheng XJ, Thompson DJ. Detailed analysis of the impact of age on the QT interval. J Geriatr Cardiol 2016;13(9):740-8 Sep.

[5] Piccirillo G, Moscucci F, Pofi R, D’Alessandro G, Minnetti M, Isidori AM, et al. Changes in left ventricular repolarization after short-term testosterone replacement therapy in hypogonadal males. J Endocrinol Invest 2019;42(9):1051-65.

[6] Piccirillo G, Moscucci F, Pascucci M, Pappadà MA, D’Alessandro G, Rossi P, et al. Influence of aging and chronic heart failure on temporal dispersion of myocardial repolarization. Clin Interv Aging 2013;8:293-300.

[7] Strait JB, Lakatta EG. Aging-associated cardiovascular changes and their relationship to heart failure. Heart Fail Clin 2012;8(1):143-64 Jan.

[8] Ocorr K, Zambon A, Nudell Y, Pineda S, Diop S, Tang M, et al. Age-dependent electrical and morphological remodeling of the Drosophila heart caused by hERG/seizure mutations. PLoS Genet 2017;13(5):e1006786. 